\section{Intern ational}

Journal of

Medical

and Surgical Sciences

\title{
Caries history and associated factors in adolescents residing in SENAME centers in Province of Concepción.
}

Johnny Stuardo ${ }^{1}$ \& Iván Sepúlveda. ${ }^{1}$

\section{ABSTRACT}

Adolescent's oral health status is able to determine not only their general health status, but also the quality of health in their adult life. Therefore, a poor oral health during adolescence might also have a negative impact on the long-term quality of life. The social determinants of health, which consist of the social conditions in which they live and develop their lives, are relevant elements in the families of these adolescents and have an impact on their health. The aim of this study is to evaluate the caries history and associated factors in adolescents residing in SENAME centers in Province of Concepción. No statistically significant differences were observed among the number of decayed, missing and filled teeth by sex, by presence of psychiatric background or by admission cause. This study analyzed a sample population with multiple risk factors, which make it more susceptible of developing alterations in oral health. The great majority of the results of our investigation proved that there weren't variables significantly connected or associated with caries history.

Keywords: prevalence, caries, adolescents, multifactorial.
Receipt:
$09 / 01 / 2019$
Revised:
$09 / 12 / 2019$
Acceptance:
$09 / 25 / 2019$
Online:
$09 / 28 / 2019$

Conflict of interests: None.

Ethics approval: Research and Bioethics Committee of the School of Dentistry, Universidad Bolivariana.

Funding: None.

Authors' contributions: All authors carried out the entire review.

Acknowledgements: None.

doi: 10.32457/ijmss.2019.015.

\section{INTRODUCTION}

Dental caries is a continuous development of different stages that increase in severity and destruction of the tooth, going from changes in the surface to dentin lesions, either with an intact or fully cavitated surface. Some of the components of the carious process act on the tooth's surface (saliva, biofilm, diet, fluoride), whereas another set of determinant factors act on individual level, such as social, economic and cultural factors (Arteaga et al., 2009).

It has been proven that an early and extensive caries disease can inhibit normal growth (Acs et al., 1999) and even predict higher levels of this disease in the future (Greenwell et al., 1990). Adolescent's oral health status is able to determine not only their general health status, but also the quality of health in their adult life. Therefore, a poor oral health during adolescence might also have a negative impact on the longterm quality of life (American Academy of Pediatric Dentistry, 2014). This population might have a high probability of tooth loss, as a result of possible trauma, since these adolescents present behavioral disorders, which increases the risk of higher emotional effects, affecting self-confidence (Davis et al., 2000) and, even in some cases, boosting depressive states of patients with psychiatric disorders (Okoje et al., 2012). Consequently, the impact of this disease on these people's health and quality of life constitutes a public health issue (Sheiham, 2005).

Generally, the cause of caries is addressed from an individual approach, ignoring structural causes and the individual's context (Fejerskov et al., 2008). The social determinants of health, which consist of the social conditions in which they live and develop their lives, are relevant elements in the families of these adolescents and have an impact on their health (Frenz, 2005). 
The National Minors' Service (SENAME) is a Chilean state institution in charge of the protection of the rights of children and adolescents at court. Most of these minors reside in centers divided by sex. Currently, there aren't epidemiological data regarding oral morbidity and associated factors of this population.

The aim of this study is to evaluate the caries history and associated factors in adolescents residing in SENAME centers in Province of Concepción.

\section{MATERIAL AND METHODS}

An observational study was carried out. The sample was composed of 82 adolescents aged between 11 and 17, residing in SENAME centers.

The inclusion criteria were: 1) subjects between 11-17 years old, 2) subjects from the SENAME centers CREAD Nuevo Amanecer from Concepción and CREAD CAPULLO from Chiguayante. Subjects excluded were: 1) those residing in centers that didn't have a clinical record or admission file, due to being admitted during the time of the exams or referred to their homes.

After obtaining the patients' informed consent, data collection was carried out through numerous visits to the nurse's offices from both SENAME centers. Sociodemographic background, such as personal data, ages, origin, admission dates, admission cause, relevant and complementary medical background, were provided by the respective nurses of each center. Oral health exam was performed according to the WHO's guidelines (1997).

All collected data were tabulated into a Microsoft Office Professional Plus Excel 2016 datasheet (MS Corp, ISA). Descriptive and analytical statistics were carried out on STATA 12/ SE (Stata Corp; USA), $p \geq 0,05$ values were considered significant.

\section{RESULTS}

The sample was composed of 82 adolescents aged between 11 and 17, female population was $47.56 \%$ and males were $52.43 \%$. The highest percentage of adolescents remained between 15 and 16 years old, with $54.87 \%$ of the total sample.

No statistically significant differences by sex were observed in anthropometric measurements, as shown in Table 1. Likewise, no statistically significant differences by sex were observed in average age and time of stay at the centers, as shown in Table 2.

In both SENAME centers, most of the adolescents under- go pharmacological treatment of psychiatric disorders, reaching $73.17 \%$. The majority of the residents are males. Regarding admission cause, Behavioral Issues were predominant in both centers with $46.34 \%$. In the female sample, violation of rights was the main cause, since there are documented cases of sexual and physical violence.

No statistically significant differences were observed among the number of decayed, missing and filled teeth by sex (see Table 3), by presence of psychiatric background (see Table 4) or by admission cause (see Table 5).

Table 1. Proportion of anthropometric measurements by sex in the sample.

\begin{tabular}{|l|c|c|c|}
\hline Sex & $\begin{array}{c}\text { Average } \\
\text { height }\end{array}$ & $\begin{array}{c}\text { Average } \\
\text { weight }\end{array}$ & $\begin{array}{c}\text { Average } \\
\text { waist }\end{array}$ \\
\hline Female & $1.60(0.07)$ & $74.69(19.63)$ & $92.20(16.45)$ \\
\hline Male & $1.66(0.08)$ & $68.19(15.18)$ & $84.53(12.63)$ \\
\hline
\end{tabular}

Table 2. Average age and months of stay of the sample by sex.

\begin{tabular}{|l|c|c|}
\hline Center & $\begin{array}{c}\text { Average } \\
\text { age }\end{array}$ & $\begin{array}{c}\text { Average } \\
\text { months of stay }\end{array}$ \\
\hline Female & $14.79(1.48)$ & $9.12(11.19)$ \\
\hline Male & $14.62(1.09)$ & $15.60(14.72)$ \\
\hline
\end{tabular}

Table 3. Distribution of decayed, missing and filled teeth index by sex.

\begin{tabular}{|l|c|c|c|}
\hline Center & Decayed & Filled & Missing \\
\hline Female & 4.07 & 2.82 & 0.61 \\
\hline Male & 3.37 & 3.37 & 0.46 \\
\hline Total & 3.72 & 3.09 & 0.53 \\
\hline
\end{tabular}

Table 4. Distribution of decayed, missing and filled teeth index by psychiatric background.

\begin{tabular}{|l|c|c|c|}
\hline $\begin{array}{l}\text { Psychiatric } \\
\text { background }\end{array}$ & Decayed & Filled & Missing \\
\hline Yes & 4.31 & 2.22 & 0.31 \\
\hline No & 3.48 & 3.06 & 0.61 \\
\hline
\end{tabular}

Table 5. . Distribution of decayed, missing and filled teeth index by admission cause of the sample's residents.

\begin{tabular}{|l|c|c|c|}
\hline Admission cause & Decayed & Filled & Missing \\
\hline Behavioral issues & 3.36 & 3.05 & 0.44 \\
\hline Violation of rights & 4.47 & 2.58 & 1.11 \\
\hline Parental negligence & 3.70 & 3.51 & 0.29 \\
\hline
\end{tabular}




\section{DISCUSSION}

This study established the prevalence and the updated status of the oral cavity of adolescents residing in SENAME centers in Province of Concepción.

Regarding DMFT index by sex, men presented a lower value than women. These results agree with those of Lukacs and Largaespada (2006), who claimed that women generally present a higher prevalence of caries than men. It is worth mentioning that the female group presented less amount of filled teeth and greater amount of missing teeth, which might be due to the lack of a local dental care network at the female facility, although they do receive dental care and must be transferred temporarily for this purpose.

No statistically significant correlation was observed between number of decayed, missing and filled teeth and admission cause. However, adolescents admitted for violation of their rights show a higher decayed teeth index, less filled teeth and greater amount of missing teeth, which is strongly noteworthy and might be due to psychosocial circumstances and intermediary factors, according to Frenz (2005).

This study analyzed a sample population with multiple risk factors, which make it more susceptible of developing alterations in oral health. The great majority of the results of our investigation proved that there weren't variables significantly connected or associated with caries history. Likewise, we observed high values of dental caries prevalence related moderately to certain risk factors, even though this population has access to dental care. This might vary considering factors such as time of stay, temporary desertion, voluntary inability for dental care and psychosocial factors of each adolescent.

\section{REFERENCES}

Acs G, Shulman R, Wain NM, Chussid S. The effect of dental rehabilitation on the body weight of children with early childhood caries. Pediatr Dent. 1999 21(2), 109-113.

American Academy of Pediatric Dentistry. Guideline on infant oral health care. USA: American Academy of Pediatric Dentistry; 2014.

Arteaga 0, Urzúa I, Espinoza I, Muñoz A, Mendoza C. Prevalencia de Caries y Pérdida de dientes en Población de 65 a 74 años de Santiago, Chile. Rev Clin Periodoncia Implantol Rehabil Oral. 2009; 2(3), 161- 166.

Davis DM, Fiske J, Scott B, Radford D. The emotional effects of tooth Ioss: a preliminary quantitative study. Br Dent J. 2000; 188(9), 503-6.

Fejerskov 0. Kidd EA, Nyvad B, Baelum V. Dental caries. The disease and its clinical management. USA: Blackwell Publishing; 2008.

Frenz P. Desafíos en salud pública de la Reforma, equidad y determinantes sociales de la salud. Rev Chil Salud Pública 2005;9(2): 103-110.

Greenwell AL, Johnsen D, DiSantis TA, Gerstenmaier J, Limbert N. Longitudinal evaluation of caries patterns form the primary to the mixed dentition. Pediatr Dent. 1990; 12(5): 278-282.

Lukacs JR, Largaespada LL. Explaining sex differences in dental caries prevalence: saliva, hormones, and "life-history" etiologies. Am J Human
Biol. 2006; 18(4):540-555.

Okoje VN, Dosumu 00, Alonge TO, Onyeaso C. Tooth loss: are the patients prepared? Niger J Clin Pract. 2012; 15(2): 172-5.

Sheiham A. Oral health, general health and quality of life. Bull World Health Organ. 2005; 83(9): 644.

WHO. Encuestas de salud bucodental. Métodos Básicos. $4^{\text {a }}$ Ed. Ginebra: Organización Mundial de la Salud; 1997. 